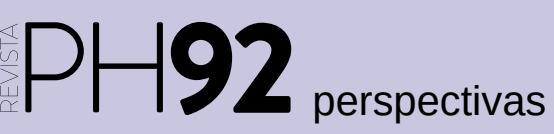

a debate Datos abiertos en instituciones culturales

| coordina Isabel Medrano Corrales

\title{
El talento gana partidos, pero el trabajo en equipo y la inteligencia ganan campeonatos
}

Alfonso Monsalve Romera | Dpto. de Prehistoria y Arqueología de la Universidad de Granada, codirector del proyecto arqueológico cerro Bilanero

URL de la contribución <www.iaph.es/revistaph/index.php/revistaph/article/view/3964>

\section{La experiencia}

Desde hace más de dos años el equipo de excavación del cerro Bilanero (Alhambra, Ciudad Real) está investigando uno de los yacimientos de la Edad del Bronce más importantes del centro peninsular (debido a su tamaño y gran estado de preservación). Estas tareas de excavación llevan consigo un intrínseco trabajo de gabinete o laboratorio, como se ha de suponer a cualquier excavación, que produce una gran cantidad de datos científicos. A posteriori esta acumulación de números, interpretaciones, dibujos, esquemas y todo un abanico de variables que introducidos en un sinfín de carpetas y discos duros sirven para la interpretación y conocimiento de la sociedad del pasado investigada. Si se me permite, como investigadores, intentamos dar a conocer a través de revistas especializadas el trabajo realizado pero es en este momento cuando surge la gran pregunta: ¿y ahora qué? ¿la publicación es el final?

Con la venia de mis compañeros, nuestras vivencias como estudiantes e investigadores noveles nos ha dado una lección. En teoría, las colecciones de materiales arqueológicos son accesibles a los investigadores pero, como muchas otras cosas, esto no ocurre. Las universidades generalmente tienen cierto derecho de admisión a la hora de consultar y (re)investigar restos de sus excavaciones arqueológicas; los museos, en otra vertiente, no suelen tener lugares para poder trabajar con una mínima comodidad ${ }^{1} ; y$, por supuesto, las empresas suelen ser poco accesibles, bien por la entrega de los materiales a las autoridades o bien por falta de tiempo o recursos. Ni qué decir tiene que muchas de estas colecciones, en ocasiones, descansan su sueño eterno en almacenes universitarios a la espera de que un osado investigador, con un machete bien afilado, quiera romper las telas de araña con nuevas teorías o

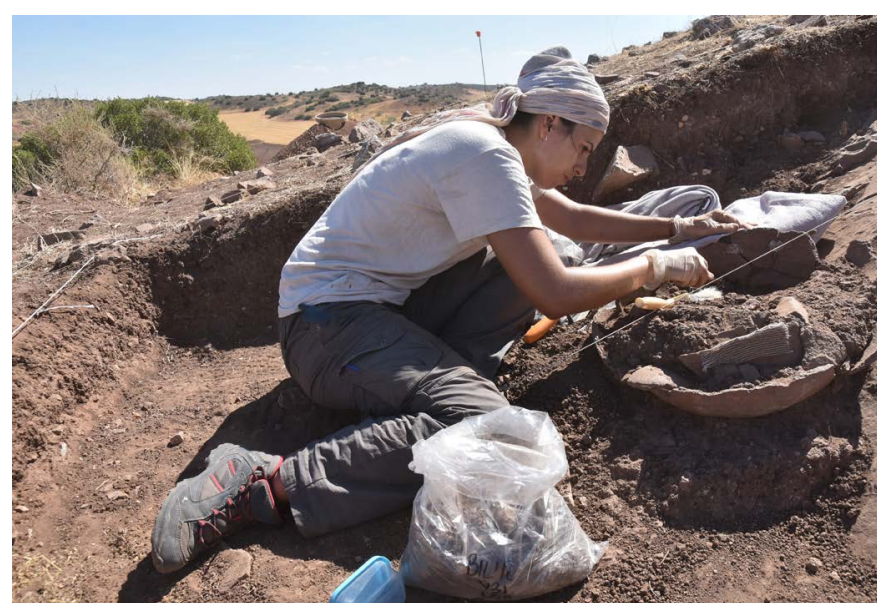

Excavación de un gran recipiente cerámico en la Unidad Estratigráfica 73 en cerro Bilanero | foto PAR. Arqueología y patrimonio virtual

ideas. Estas ideas, en ocasiones, no suelen encajar con las del cuerpo directivo de las investigaciones realizadas con anterioridad perdiendo así el potencial trabajo de una persona, foránea a su equipo de investigación, capacitada para realizar una investigación de índole arqueológica.

La coyuntura comentada anteriormente, y que muchos jóvenes investigadores hemos sufrido, lleva consigo a una pérdida de conocimiento que en España (particularmente) parece sobrar. En otras ocasiones, acaba con trabajos de máster o tesis doctorales preadaptadas por un tutor o tutora (que generalmente suele coincidir con la dirección de las excavaciones o colaboradores) que dicta a su joven tutelado una tesis con resultados y temas elegidos con anterioridad (de forma consciente o inconsciente) y que motiva poco, o muy poco, al verdadero investigador ya que tiene pocos márgenes de libertad sobre el discurso científico expuesto previamente. Son lentejas. 


\section{Imaginando un nuevo modelo desde el Cerro Bilanero} Desde el Cerro Bilanero entendemos la necesidad de que todas las personas, investigadores y ciudadanía, puedan tener acceso a los datos extraídos del registro arqueológico y los materiales del yacimiento. En la actualidad se trabaja en una gran base de datos que abarca todas las particularidades que se puedan necesitar para realizar una reinterpretación de la excavación o de las hipótesis planteadas ${ }^{2}$. Debido a nuestra experiencia tratamos de evitar la inaccesibilidad a cualquier interesado por dos motivos: nosotros no somos dueños del material arqueológico ni del yacimiento y, segundo, no nos molesta que cualquier persona pueda aportar, desde un punto de vista científico, nuevas interpretaciones. Se entiende que el equipo de investigación del Cerro Bilanero no es perfecto y, aunque queramos hacerlo lo mejor posible, nada es perfecto. La llegada de hipotéticos investigadores que puedan reinterpretar las hipótesis planteadas no es una crítica a nuestro trabajo; es tan sólo mejorarlo y ofrecer nuevas perspectivas. Por supuesto, esta base de datos no puede ser simplemente accesible; debe de ser en abierto, sin restricciones, sin contraseñas ni bendiciones.

Imaginemos ahora que no sólo el Cerro Bilanero promueve esta idea ${ }^{3}$. Imaginemos que es obligatorio para cualquier excavación o intervención en el ámbito de la cultura o investigación. Imaginemos que podemos realizar análisis comparativos, usar estas herramientas para que alumnos y estudiantes mejoren su formación o simplemente que un curioso ciudadano por su cuenta quiera saber qué y cómo se investigan restos que en su proporcionalidad como ciudadano español son de su propiedad. ¿No estaría mal, no? Apliquemos esta teoría (hoy por hoy un sueño) a cualquier ámbito, como por ejemplo, la cura del cáncer o enfermedades raras. Serían pocas las personas que no estarían a favor de la cura del cáncer.

Los datos en abierto mejorarían e incrementarían la capacidad investigadora de nuestro país y, en otra vertiente, paliarían la falta de inversión en ciencia. Nosotros particularmente no tenemos miedo a colgar estos datos, si la ley lo permite (que eso es otro cantar) pero entendemos que este país y su colectivo científico sufren dos enfermedades comunes a muchos investigadores: La articulitis y un síndrome agudo por lo inédito del yo, yo mismo y mi mismidad. No, no es su culpa, no hay que señalar al eslabón débil de la cadena. La culpa es de la baja inversión en ciencia que permite una verdadera carrera de lobos por un puesto de trabajo con un salario mediocre o una beca mal pagada.

Creemos firmemente que la ciencia en España no ha avanzado mucho en este campo y que, como científicos, faltamos a nuestro principal objetivo que es mejorar las condiciones de vida del ser humano. Hagamos una reflexión, ayudémonos y seamos entre todos uno. Como decía el 23 de los Chicago Bulls (Michael Jordan) "El talento gana partidos, pero el trabajo en equipo y la inteligencia ganan campeonatos". No tengamos miedo a que nuestros datos en abierto puedan ser consultados y reinterpretados ya que con ello mejoraremos la vida de todos. Dejemos libertad al talento y no a los discursos vanos de multidisciplinariedad.

\section{NOTAS}

1. No es extraño ver una pequeña sala con una mesa, un flexo, sin calefacción, sin conexión a Internet, sin una explicación previa del lugar, con suciedad y otros factores que impiden realizar con un mínimo de comodidad tareas de investigación.

2. Planimetrías, dibujos, fichas de unidades, descripción de piezas, fotografías, etc.

3. Otros como la Universidad de Jaén lo hicieron con anterioridad a través del Centro Andaluz de Arqueología Ibérica y su Proyecto CATA, por ejemplo. 